\title{
2 Process and Prospect for Control and Prevention 3 Impairment of Water-borne Iodine Excess in China
}

\author{
4 Peng Liu, Lijun Fan, Xiaohui Su, Fangang Meng, Hongmei Shen*
}

Key lab of Etiology and Epidemiology, Education Bureau of Heilongiiang Province \& Ministry of Health, Center for Endemic Disease Control, Chinese Center for Disease Control and Prevention, Harbin Medical University, Harbin 150081, China.; HM S Email: shenhm119@ hrbmu.edu.cn; Tel:+86-86625428; PL, Email: liup7878@163.com; Tel:+86-86675819; LJ F, ffistar@163.com; Tel:+86-86675814; XH S, suxiaohui8@163.com, Tel:+86-86675819; FG M, mfg5181397@163.com, Tel:+86-86675814

Abstract: Since the water-borne iodine excessive goiter was firstly found and reported in 1978 in Hebei Province, it was confirmed successively. The national water-borne investigation carried out in 2005 demarcated the water-borne iodine excess areas and water-borne iodine excess endemial areas. The high iodine water well was found In 129 counties of 11 provinces, about 30.98 million people of threatened population lived in water-borne iodine excess areas and water borne iodine excess endemial areas. In these areas, the measures of prevention and control was effectively implemented. In 2016, the new standard of iodine excess area was issued, the iodine excess areas should be redrawed, and in these areas, non-iodized salt should be supplied and the drinking water should be gradually improved of water, and to control the damage of water-borne iodine excess at an early date.

Key words: water-borne; iodine excess; impairement; control and prevention

\section{Introduction}

Iodine is a micronutrient that is essential for the production of thyroid hormones. Recommended daily iodine intake is $150 \mu \mathrm{g}$ in adults who are not pregnant or lactating. Ingestion of iodine or exposure above this threshold is generally well-tolerated. However, in certain susceptible individuals, including those with pre-existing thyroid disease, the elderly, fetuses and neonates, or patients with other risk factors, the risk of developing iodine-induced thyroid dysfunction might be increased[1]. Excessive iodine intake may cause thyroid goitre, overt hyper- and hypothyroidism, subclinical hyper- and hypothyroidism, autoimmune thyroid disease, iodine allergies and iodine poisoning, loss of intelligence, etc.[2-7]. Although few articles presented the relationship between iodine excess and thyroid carcinoma, concrete evidence are still needed. Iodine excess can be seperated into water-borne and food-borne by its source. In some paticular places, the source of the excess iodine might not be readily apparent [8-9]. China is the first country to find water-borne iodine excess, which has been found in 13 provinces, municipalities and autonomous regions since 1978 [10$14]$.

\section{The Discovery and Confirmation of the Water-borne Iodine Induced Goiter}

In 1978, high goiter prevalence caused by drinking-water iodine excess was first discovered in Huanghua, a county of Hebei Province, China. Hebei Medical Collage primarily investigated this phenomenon. After compared the chemical composition in deep groundwater and shallow-well water and investigate the thyroid morphology and function, and iodine metabolic states of local residents, they found that the goiter prevalence was $7.3 \%$ in the 4344 residents who drink the deep groundwater; the iodine content in the deep groundwater was $961.2 \mu \mathrm{g} / \mathrm{L}$; and the urine iodine concentration was $1645.3 \mu \mathrm{g} / \mathrm{g}$ cr and $2560 \mu \mathrm{g} / \mathrm{g}$ cr for men and women, respectively. 
Since 1978, the existance of iodine induced goiter was confirmed successively through epidemiology, clinical and animal experiments. A number of studies investigated the decline of goiter rates before and after improving water through changing the well depth by Hebei Medical College. Citizens lived in Zhangjuhe Village, a coastal village in Hebei Province, drinking shallow well water which contained $34.5 \mu \mathrm{g} / \mathrm{L}$ iodine until 1978. The prevalence of goitre was $2.83 \%$ respectively in these citizens. However, after changing to the deep groundwater in 1978, the water iodine content was raised to $306-450 \mu \mathrm{g} / \mathrm{L}$, the prevalence of goitre rate elevated to $19.86 \%$, respectively, which almost arrived at the level of public health issue.

In order to further demonstrate the relationship between iodine-rich water and thyroid enlargement, surveys about drinking water iodine contents and goiter prevalence were undertaken in several counties. Associations between water iodine levels and thyroid enlargement were: when the water iodine was lower than $95.5 \mu \mathrm{g} / \mathrm{L}$, goitre rate was generally low $(<5 \%)$. When water iodine exceeded $200 \mu \mathrm{g} / \mathrm{L}$, endemic goiter occurred in this area. The prevalence of goiter was positively related with iodine content in drinking water, the trend was significant $(p<0.05)$ and the correlation coefficient was 0.93 .

It showed that the iodine content in drinking water had a dose-response relationship with endemic goiter in the population. According to a series of epidemiological investigation, the reason of why endemic goiter become more prevalent in one area than others was attributed to the excessive iodine intake from the drinking water.

To verify the endemic goiter in those areas were caused by iodine excess, and confirm there was a dose-response relationship between iodine and goiter prevalence, animals experiments on Leghorn chicken and Kunming mouse were conducted by Hebei Medical College. These experiments also showed positive results between high iodine and goiter.

Water improvement decreased the prevalence of iodine induced goiter. In Xinglong Village, which was located in central plain of Hebei Province, before improving water to reduce iodine, the water iodine content was $559.0 \mu \mathrm{g} / \mathrm{L}$, urine iodine content was $1053.64 \mu \mathrm{g} / \mathrm{g} \mathrm{cr}$, goiter rate in citizen was $4.5 \%$, goiter rate in children aged $8 \sim 10$ was $29.03 \%$. However, after drinking the optimal iodine water (the water iodine content was $44.0 \mu \mathrm{g} / \mathrm{L}$ ) for seven months, the urine iodine content was declined to $102.05 \mu \mathrm{g} / \mathrm{g} \mathrm{cr}$, the goiter rate in citizen was dropped to $0.62 \%$, goiter rate in children aged $8 \sim 10$ fell to $13.41 \%$, which indicated that the iodine excess was corrected. In the meantime, the water iodine, urine iodine and goiter prevalence did not change at all in control area.

Based on these mentioned epidemiological surveys, animal experiments and observational studies on water improvement, it was concluded that endemic goiter occurred in coastal villages near Bohai Bay and in part of plain was induced by high iodine drinking water. In order to separated it from food-borne iodine excess induced by seaweeds, this type of goiter was named as endemic "Water-borne Iodine Excess Goiter".

This study was conducted according to the guidelines established in the Declaration of Helsinki, and the project was approved by the Ethics Committee of Harbin Medical University (No. HMUe17.n11), which was approved in November, 9th, 2017. For the field investigation mentioned in the article, written informed consent was obtained before the investigation began from the pregnant women, lactating women, and adults, and for children, permission was obtained from guardians

\section{Water-borne Iodine excess area Discovered Followed}

In 1985, investigation about the water-borne iodine excess goiter in Hebei Province demonstrated, in the "Plain-type Iodine Excess area" of Hebei Province, iodine excess goiter was found in some low-lying and obstructed plains, including Xincheng and Xiong County in Baoding area, Yongqing and Gu'an in Langfang area, Guangzong and Wei County in Xingtai area. This type of goiter was named as "Plain-type Iodine Excess Goiter" as being found in plains. 
15

In 1986, the "Inland-type Iodine Excess Goiter" was disecoverd in Shanxi Province. Qian Qidong reported that the iodine content in shallow groundwater was $533.8 \mu \mathrm{g} / \mathrm{L}$, median of urine iodine concentration was $2428.5 \mu \mathrm{g} / \mathrm{L}$ and the goiter rate was about $32.54 \%$ in Xiaoyi County of Shanxi Province[15]. As found in the west of Taihang Mountain, it was also called as "Inland-type Iodine Excess Goiter". "Water-borne Iodine Excess Goiter" were also found in some low-lying villages in more than 10 counties which located on Jinzhong Basin in Liu Derun's report.

From 1983 to 2003, the Water-borne Iodine excess areas was found in Shandong, Xinjiang, Fujian, Henan, Inner Mongolia, Anhui, Jiangsu, Beijing, Tianjin and Shaanxi. In 2013, median of water iodine were over $150 \mu \mathrm{g} / \mathrm{L}$ in 14 villages of five counties near Jianjiang river basin in Guangdong Province. In 2017, during the project of national drinking-water iodine investigation in China, high water iodine well was found in Chengbu county of Hunan Province.

\section{National Investigation in Water-borne Iodine Excess Areas}

In 2005, in order to explore the distribution of drinking-water with high iodine in China, a national water-borne iodine excess areas survey was launched by Center for Endemic Disease Control, Chinese Center for Disease Control and Prevention. This survey was granted by the Public Health Fund sponsored by the central government. The results showed that iodine excess is mainly caused by naturally occurred with high iodine in drinking water. Wells with high water iodine were found in 129 counties of 11 province, municipality and autonomous regions including Anhui, Beijing, Fujian, Hebei, Henan, Jiangsu, Inner Mongolia, Shandong, Shanxi, Tianjin and Xinjiang. Water-borne iodine excess areas (goiter prevalence $<5 \%$ ) existed in all these provinces except Fujian and Xinjiang, and water-borne iodine excess endemial areas (goiter prevalence $>5 \%$ ) existed in all these provinces except Fujian, Xinjiang, Beijing and Inner Mongolia. A total of 96 counties contained water-borne iodine excess villages and 64 counties contained water-borne iodine excess endemial villages, table 1. About 30.98 million people lived in the water-borne iodine excess or endemial areas [9].

Table 1 The distribution of water-borne iodine excess areas in 2005

\begin{tabular}{|c|c|c|c|c|c|c|c|c|}
\hline $\begin{array}{c}\text { Provin } \\
\text { ce }\end{array}$ & $\begin{array}{c}\text { Contie } \\
\text { s with } \\
\text { HWI } \\
\end{array}$ & $\begin{array}{c}\text { Counites } \\
\text { with } \\
\text { HWI } \\
\end{array}$ & $\begin{array}{c}\text { Counites } \\
\text { with HWI } \\
\text { endemial }\end{array}$ & $\begin{array}{c}\text { Towns } \\
\text { hips } \\
\text { with } \\
\end{array}$ & $\begin{array}{l}\text { Town } \\
\text { ships } \\
\text { with } \\
\end{array}$ & $\begin{array}{c}\begin{array}{c}\text { Populat } \\
\text { ion in } \\
\text { HWI }\end{array} \\
\end{array}$ & $\begin{array}{c}\text { Towns } \\
\text { hips } \\
\text { with } \\
\end{array}$ & $\begin{array}{l}\text { Populatio } \\
\mathrm{n} \text { in } \mathrm{HWI} \\
\text { endemial }\end{array}$ \\
\hline Beijing & 1 & 1 & 0 & 6 & 1 & 30 & 0 & 0 \\
\hline Tianjin & 2 & 2 & 1 & 19 & 11 & 110 & 4 & 320 \\
\hline Hebei & 38 & 26 & 22 & 243 & 108 & 3780 & 63 & 2020 \\
\hline Shanxi & 10 & 7 & 6 & 42 & 18 & 470 & 11 & 410 \\
\hline $\begin{array}{l}\text { Inner } \\
\text { Mongol }\end{array}$ & 2 & 1 & 0 & 18 & 2 & 40 & 0 & 0 \\
\hline Jiansu & 6 & 6 & 5 & 127 & 40 & 1520 & 48 & 2300 \\
\hline Anhui & 10 & 3 & 2 & 90 & 15 & 880 & 21 & 1090 \\
\hline Fujian & 1 & 0 & 0 & 3 & 0 & 0 & 0 & 00 \\
\hline Shando & 40 & 33 & 19 & 442 & 189 & 8800 & 58 & 3650 \\
\hline Henan & 18 & 17 & 9 & 312 & 104 & 3240 & 41 & 2320 \\
\hline Xinjian & 1 & 0 & 0 & 2 & 0 & 0 & 0 & 0 \\
\hline Total & 129 & 96 & 64 & 1304 & 488 & 18870 & 246 & 12110 \\
\hline
\end{tabular}

Note: HWI, high water iodine.

\section{5. Investigation on other Iodine Excess Impairment}


The follow-up studies found that high iodine intake could increase the prevalence rate of hyperthyroidism, thyroid hypofunction and autoimmune thyroid disease besides goiter.

It is controversial about whether high iodine intake can cause children's intellectual impairment. Qian et al. reported that the mean effect size of iodine excess on intelligence was 0.21 , and iodine excess had not shown significant important role in children's intelligence in a Meta-analysis[16]. Ren et al. reported that iodine content greater than $600 \mu \mathrm{g} / \mathrm{L}$ would reduce the intellectual level of children in a computerized literature research [17].

It is also found that high iodine may improve the prevalence of cardiovascular disease. Guo et al. found that there was a link between Budd-Chiari syndrome and high iodine in external environment [18].

Studies have demonstrated that subclinical hypothyroidism was related with miscarriage, premature birth, stillbirth, fetal intrauterine growth retardation and a series of adverse pregnancy outcomes. Therefore, iodine excess may be an important factor which causes the adverse pregnancy outcomes.

\section{National Criterion of the Delimitation and Demarcation of Water-borne Iodine Excess Areas and Endemial Areas}

"Determination and classification of the areas of high water iodine and the endemial areas of iodine excess goiter" (GB/T 19380-2003) was led by Liu, a chief physician in the Institute for Endemic Disease Control and Research of Shanxi Province [19]. According to this standard, an area can be considered as high water iodine area if it complies with: i) the median of iodine content in drinking water is more than $150 \mu \mathrm{g} / \mathrm{L}$; $\mathrm{ii}$ ) the median urinary iodine of children aged 8-10 is over $400 \mu \mathrm{g} / \mathrm{L}$. An endemial areas of iodine excess goiter complies with: i)the median of iodine content in drinking water is more than $300 \mu \mathrm{g} / \mathrm{L}$; ii ) the median urinary iodine of children aged $8-10$ is over $800 \mu \mathrm{g} / \mathrm{L}$; iii) the goiter rate of children aged 8-10 is greater than 5\%. These areas are delimitated on the basis of township considered of the distribution characteristics and the manipuility of intervening measures such as supplying non-iodized salt.

Jia, a chief physician in the institute for endemic disease control and research of Shanxi Province, led the revision of the standard since 2007. The revision complied: i) the name was corrected as "Definition and demarcation of water-borne iodine-excess areas and iodine-excess endemial areas" (GB/T 19380-2016) [20]; ii) the areas were defined as village instead of township; iii) the indicators of water-borne iodine excess area were altered to: the median of iodine concentration in drinking water is more than $100 \mu \mathrm{g} / \mathrm{L} ; \mathrm{iv}$ ) the indicators of endemial areas of iodine excess goiter were altered to: the median of iodine content in drinking water is more than $100 \mu \mathrm{g} / \mathrm{L}$ (compulsory indicator); the goiter rate of children aged 8-10 is higher than 5\% (compulsory indicator); the median urinary iodine of children aged 8-10 is over $300 \mu \mathrm{g} / \mathrm{L}$ (reference indicator). The revised standard has been released in 2016, table 2 .

Table 2 The old and new standard of iodine-excess area and endemial area
Iodine-excess area

Iodine-excess endemial area

\section{GB/T 19380-2003}

Determination and classification of the areas of high water iodine and the endemial areas of iodine excess goiter"
(1) the median of iodine content in drinking water is more than $150 \mu \mathrm{g} / \mathrm{L}$;

(2) the median urinary iodine of children aged $8-10$ is over $400 \mu \mathrm{g} / \mathrm{L}$
(1) the median of iodine content in drinking water is more than $300 \mu \mathrm{g} / \mathrm{L}$; (2) the median urinary iodine of children aged $8-10$ is over $800 \mu \mathrm{g} / \mathrm{L}$;

(3)the goiter rate of children aged 8-10 is greater than $5 \%$ 


\section{GB/T 19380-2016}

Definition and demarcation of waterborne iodine-excess areas and iodine-excess endemial areas the median of iodine concentration in drinking water is more than $100 \mu \mathrm{g} / \mathrm{L}$
(1) the median of iodine content in drinking water is more than $100 \mu \mathrm{g} / \mathrm{L}$ (compulsory indicator);

(2) the goiter rate of children aged 8-10 is higher than $5 \%$ (compulsory indicator); (3) the median urinary iodine of children aged $8-10$ is over $300 \mu \mathrm{g} / \mathrm{L}$ (reference indicator)

\section{6}

\section{Fulfillment of Intervention Measures}

In order to prevent iodine deficiency disorders, comprehensive prevention and control measures including universal salt iodization were implemented since 1995 in China.

China's "Regulation on Edible Salt Iodisation as a Means to Eliminate IDD" specifies that iodine salt should not be distributed in iodine excess areas. The scopes of water-borne iodine excess areas were more explicit than before. So far, non-iodized salt has been supplied in these areas instead of iodized salt, and they were surveyed from 2007 as a measure of prevention and control measure, table 3.

Table 3 Coverage rate of non-iodized salt in water-bone iodine excess area from 2007 to 2016 surveillance

\begin{tabular}{cccccc}
\hline Year & $\begin{array}{c}\text { No. of } \\
\text { province }\end{array}$ & $\begin{array}{c}\text { No. Of } \\
\text { Counties }\end{array}$ & $\begin{array}{c}\text { Sample } \\
\text { size }\end{array}$ & $\begin{array}{c}\text { No. Of non- } \\
\text { iodized salt }\end{array}$ & $\begin{array}{c}\text { Coverage rate of } \\
\text { non-iodized salt } \\
(\mathbf{\%})\end{array}$ \\
\hline 2007 & 5 & 78 & 21321 & 15594 & 73.1 \\
2008 & 8 & 84 & 19462 & 16114 & 82.8 \\
2009 & 8 & 84 & 19062 & 17262 & 90.6 \\
2010 & 8 & 110 & 24692 & 19334 & 78.3 \\
2011 & 7 & 109 & 24492 & 22245 & 90.8 \\
2012 & 8 & 110 & 25961 & 23923 & 92.1 \\
2013 & 8 & 110 & 26040 & 24919 & 95.7 \\
2014 & 8 & 110 & 25679 & 24545 & 95.6 \\
2015 & 8 & 110 & 25597 & 24640 & 96.3 \\
2016 & 8 & 110 & 26280 & 25339 & 96.4 \\
\hline
\end{tabular}

Water improvement measures were also taken in order to reduce the high iodine intake from water in some areas. This work had already been finished in Beijing, Fujian, Inner Mongolia and Shaanxi.

In other provinces, the constructions of water supply system was developed with the funds supplied by "Drinking Water Safety Projects in Rural Areas in the Eleventh-five Year" and "Preventing and Controlling High Fluorine and High Arsenic Project" of National Development and Reform Commission. However, water iodine is not an indicator for choosing water source in those projects. 


\section{Implementation of National Surveillance in Water-borne Iodine Excess Area and Endemial Area}

Water-borne iodine excess areas surveillance program has been conducted in water-borne iodine excess areas and endemial areas in the relevant provinces by national Center for Endemic Disease Control from 2012. The purpose of this surveillance program included: knowing the consumption of non-iodized salt in water-borne iodine excess areas and endemial areas timely; learning the current situation of iodine changed in the environment and the status of iodine excess goiter; keeping healthy of the residents who lived in water iodine excess areas, and providing scientific basis for government to make prevention and control strategy. This surveillance program is conducted once a year and monitoring including iodine in household salt, drinking-water iodine and iodine-excess goiter.

\section{The Major Issues during Control and Prevention of Water-borne Iodine Excess Impairment}

There were also several issues during prevention and control of water-borne iodine excess impairment. First, it is still obscure about the distribution of the water-borne iodine excess areas in the village level in most provinces although new standards for the water iodine excess areas have been issued. The water iodine excess areas and endemial areas should be determined and classified timely. Second, prevention and control measures should be strengthened to make sure that the edible non-iodized salt can be provided to all citizens lived in water iodine excess areas. Third, except Beijing, Inner Mongolia, Xinjiang, Shaanxi and Fujian, other provinces have not yet improved water to reduce iodine in water iodine excess areas. How to take the water improving program as a project for the water department in these areas is a main problem. Forth, health education in water iodine excess areas has not been carried out. Fifth, the impact of iodine excess for body health is not clear, and it needs further scientific research.

\section{Prospective and Suggestion on Control and Prevention of Water-borne Iodine Excess} Impairment

\subsection{Redraw the High Water Iodine areas according to the new standard}

In the current version of "Definition and demarcation of water-borne iodine-excess areas and iodine-excess endemial areas" (GB/T 19380-2016), the endemic area was defined by county instead of village, and the criteria of water iodine changed from iodine levels higher than $150 \mu \mathrm{g} / \mathrm{L}$ to any area where the iodine content is higher than $100 \mu \mathrm{g} / \mathrm{L}$. Reducing the cut-off for high water iodine areas will increase the number of affected areas. It is important to check the water iodine distribution in county level and know how many townships and villages will be categorized as high water iodine under the new cut-off level.

\subsection{Improve Water to Reduce Iodine in Water-borne Iodine-excess Areas}

The method of improving water to reduce iodine can effectively prevent and control the prevalence of endemic goiter in water-borne iodine-excess endemial areas. Therefore, the water iodine distribution should be checked out in village level by the health department and then provided to the local water conservancy department. The water conservancy department should take the water improving program as an important project in water-borne iodine-excess areas, and control the impairment of iodine excess as early as possible.

\subsection{Improve the Salt Market Supervision and Guarantee the Non-iodized Salt Supplement}

As the intersection of water-borne iodine-excess areas, with the iodine deficiency areas and optimal iodine areas, it brought some difficulties for salt supplyment. In recent years, the rate of noniodized salt consumption remained about $90 \%$ in water-borne iodine-excess areas, this number implied that there are parts of citizens still choose iodized salt. Iodine excess water and iodized salt will bring double hazards for the citizen. Therefore, the market supervision department of the salt 
218 industry should strengthen the market management to ensure that all residents of the water-borne 219 iodine-excess areas eat the non-iodine salt.

22010.4 Develop the Surveillance in Water-borne Iodine-excess Areas, Improve the Surveillance System

As the implementation of "Definition and demarcation of water-borne iodine-excess areas and iodine-excess endemial areas" (GB/T 19380-2016), the Center for Endemic Disease Control will revise the surveillance program, and the water-borne iodine-excess areas will be defined by village in future.

\subsection{Carry out Health Education and Health Promotion in Water-borne Iodine-excess Areas}

Material of health education for water-borne iodine-excess areas should be made according to the current situation of prevention and control in water-borne iodine-excess areas. Health education and health promotion should be carried out for protecting from iodine excess impairment. Through acknowleged the harm of iodine excess, citizen can choose non-iodized salt and drink low iodine water consciously. Improving the health education and promotion among leaders and relevant departments, and supervising water departments improving water to reduce iodine in these areas should be fullfiled as soon as possible.

\subsection{Conduct Scientific Research about the Impairment of Iodine Excess}

As water-borne iodine-excess areas was first been found in China, many people lived in the water-borne iodine-excess areas until now and in view that the impairment of iodine excess is still not very clear, it is suggested that epidemiological investigation on iodine excess hazards and pathogenesis research should be strengthen in future.

Acknowledgments: This work was supported by a grant from the National Science Foundation of China (NSFC81573098).

Author Contributions: “H.M.S. and X.H.S. conceived manuscript; L.J.F and F.G.M analyzed the data; H.M.S and P.L. wrote the paper."

Conflicts of Interest: The authors declare no conflict of interest. The founding sponsors had no role in the design of the study; in the collection, analyses, or interpretation of data; in the writing of the manuscript, and in the decision to publish the results.

\section{References}

1. Leung A. M.; Braverman L. E. Consequences of excess iodine [J]. Nat Rev Endocrinol 2014, 10, 136-142.

2. Yu Z.; Zhu H.; Chen Z.; et al. Progress in endemic iodine excess goiter (2). Chin J Endemiol 1999, 18, 385387.

3. Bournaud C.; Orgiazzi J.J. Iodine excess and thyroid autoimmunity. J Endocrinol Invest 2003, 26, Suppl. 2, $49-56$.

4. $\quad$ Teng W.P.; Shan Z.Y.; Teng X.C.; et al. Effect of iodine intake on thyroid diseases in China. N Engl J Med 2006, 354, 2783-2793.

5. Li Y.; Teng D.; Shan Z.; et al. Antithyroid peroxidase and antithyroglobulin antibodies in a five-year followup survey of population with different iodine intakes. J Clin Endocrinol Metab 2008, 93, 1751-1757.

6. Liu H.L.; Lam L.T.; Zeng Q.; et al. Effect of drinking water with high iodine concentration on the intelligence of children in Tianjin. China. J Public Health 2009, 31, 32-38. 
7. Aakre I.; Strand T.A.; Moubarek K.; et al. Associations between thyroid dysfunction and developmental status in children with excessive iodine status. PloS one, 2017, 12, e0187241.

260 8. Mu L.; Chengyi Q.; Qidong Q.; et al. Endemic goitre in central China caused by excessive iodine intake $261 \quad$ Lancet, 1987, 330, 257-259.

9. Hongmei S. The provention and control status and counter measures of iodine deficiency disease and water-borne iodine excess impairment in China. Clin J Endemiol, 2012, 31, 239-240.

264 10. Zhiheng Y. Discovery and confirmation of water-borne Iodine excess goiter. Chin J Endem 1988, 3, 91-94.

11. Zhiheng Y.; Huimin Z.; Congyi C.; et al. Research progress of the association between high water iodine and goiter (the first one). Chin J Endem, 1999, 18, 301.

12. Jingzhong Z.; Chunhe G.; Zhiheng Y.; et al. The distribution and prevalence of iodine excess goiter in Hebei province. Chin J Prev Med, 1987, 21, 296-299.

269 13. Qidong Q.; Deren L.; Dedu C.; et al. Endemic inland goiter. Chin J Endem, 1986, 5, 40-43.

14. Hongmei S.; Shubin Z.; Xiaohui S.; et al. Study on the geographic distribution of national high water iodine areas and the contours of water iodine in high iodine areas. Chin J Endem, 2007, 26, 658-661.

15. Qidong Q. Endemic inland iodide goiter. Chin J Endem, 1986, 1, 14.

16. Qian M.; Yan Y.; Chen Z.; et al. Meta-analysis on the relationship between children's intelligence and factors as iodine deficiency, supplement iodine and excessive iodine Chin J Epidem 2002, 23, 246-249.

17. Ren S.; Zhong Z. Meta-analysis on the relationship between Chinese children's intelligence and excessive iodine J Hygi Res 2014, 43, 133-138. http://europepmc.org/abstract/med/24564126

18. Guo C.; Bian J.; Wang Y.; et al. Effects of multiple elements in drinking water on inferior vena cava membranous obstruction type of the Budd-Chiari syndrome in Heze area of Shandong Province. Chin J Endem, 2005, 2.

19. Derun L.; Jinkou Z.; Huimin Z.; Xiaowei G.; Yu W. Determination and classification of the areas of high water iodine and endemic areas of iodine excess goiter. (GB/T 19380-2003).National Standard of People's Republic of China, 2003.

20. Qingzhen J.; Xiangdong Z.; Hongmei S.; et al. Definition and demarcation of water-borne iodine-excess areas and iodine-excess endemial areas (GB/T 19380-2016). National Standard of People's Republic of China, 2016. 


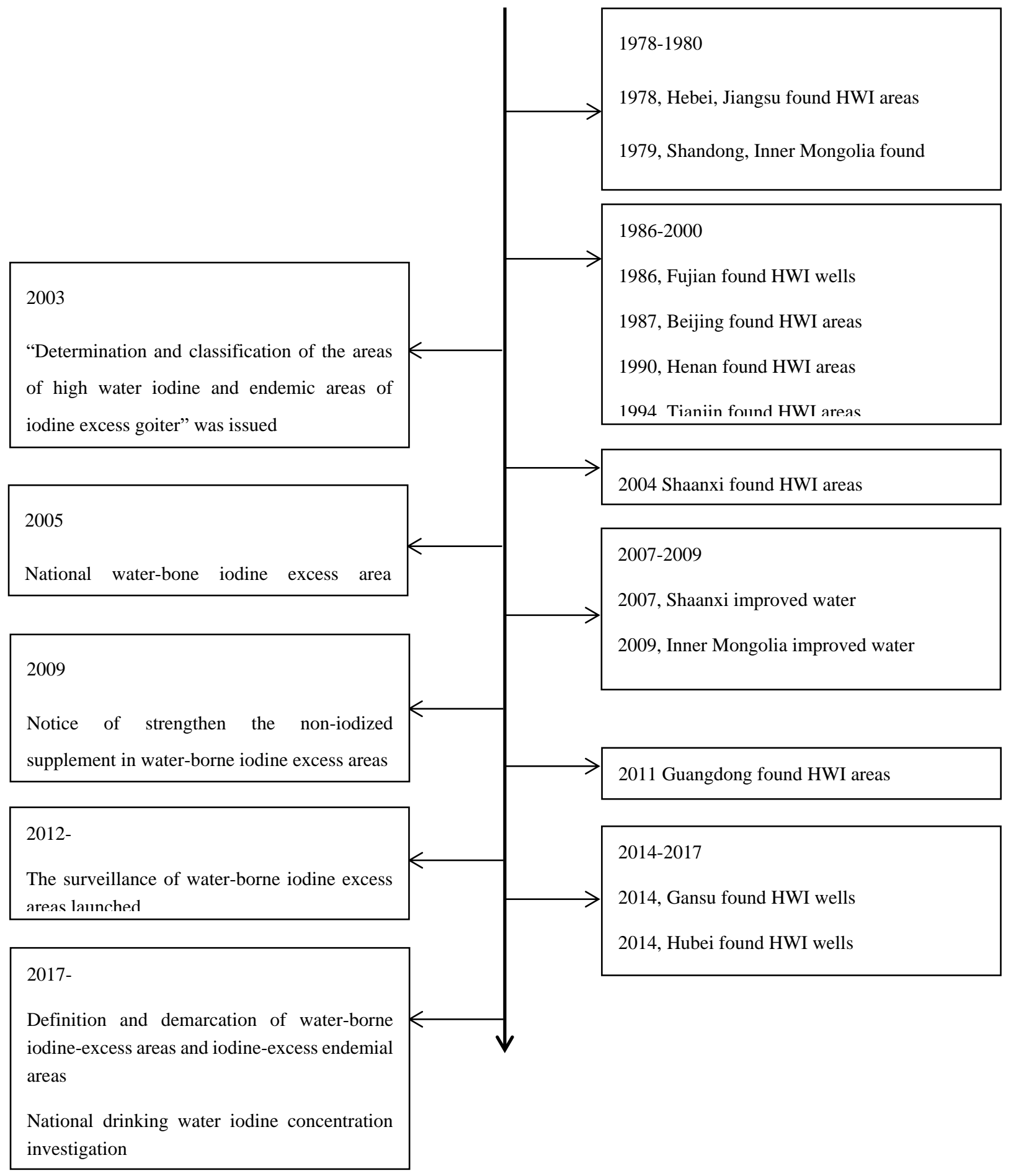

